\title{
Immunoexpression of human leukocyte antigen-DR in actinic cheilitis and lower lip squamous cell carcinoma
}

\author{
Luana Samara Balduíno de \\ SENA ${ }^{(a)}$ \\ Hellen Bandeira de Pontes \\ SANTOS ${ }^{(b)}$ \\ Marina Gonçalves do AMARAL(a) iD \\ Manuel Antonio \\ GORDÓN-NÚÑEZ(a) \\ Pollianna Muniz ALVES(a) iD \\ Cassiano Francisco Weege \\ NONAKA $^{(a)}$ iD \\ (a) Universidade Estadual da Paraíba - UEPB, \\ Department of Dentistry, Campina Grande, \\ PB, Brazil. \\ (b) Universidade Federal do Rio Grande \\ do Norte - UFRN, Department of Oral \\ Pathology, Natal, RN, Brazil.
}

Declaration of Interests: The authors certify that they have no commercial or associative interest that represents a conflict of interest in connection with the manuscript.

Corresponding Author:

Cassiano Francisco Weege Nonaka

E-mail: cfwnonaka@gmail.com

ht1ps://doi.org/10.1590/1807-3107bor-2019.vol33.0085

Submitted: December 7, 2018

Accepted for publication: July 2, 2019

Last revision: August 1, 2019
Abstract: The aim of this study was to evaluate the immunoexpression of human leukocyte antigen-DR (HLA-DR) in actinic cheilitis (AC) and lower lip squamous cell carcinoma (LLSCC), and to correlate the findings with clinical (tumor size/extent, regional lymph node metastasis, and clinical stage) and histopathological (grade of epithelial dysplasia and inflammatory infiltrate for $\mathrm{AC}$ and histopathological grade of malignancy for LLSCC) parameters. Twenty-four AC and 48 LLSCC cases (24 with regional nodal metastasis and 24 without regional nodal metastasis) were selected. The scores of immunopositive cells for HLA-DR in the epithelial component of the lesions were assessed and the results were analyzed statistically using the nonparametric Mann-Whitney test. Epithelial expression of HLA-DR was observed in only five $(20.8 \%)$ cases of AC (two low-grade and three high-grade lesions), with a very low median score of immunopositivity. By contrast, expression of HLA-DR was found in most LLSCC (97.9\%), with a relatively high median score of positive cells. The score of HLA-DR-positive cells tended to be higher in tumors with regional lymph node metastasis, tumors in advanced clinical stages, and low-grade tumors, but the difference was not statistically significant $(\mathrm{p}>0.05)$. In addition, there was a tendency towards higher expression of HLA-DR in highly/moderately keratinized tumors, and tumors with little/moderate nuclear pleomorphism ( $p>0.05)$. The results suggest a potential role of HLA-DR in lip carcinogenesis, particularly in the development and progression of LLSCC. The expression of this protein can be related to the degree of cell differentiation in these tumors.

Keywords: Actinic Cheilitis; Carcinoma, Squamous Cell; Lip; HLA-DR Antigens; Immunohistochemistry.

\section{Introduction}

Lower lip squamous cell carcinoma (LLSCC) is one of the most frequent malignancies of the oral cavity and its development is associated with some risk factors, especially with chronic exposure to the sun's ultraviolet radiation. ${ }^{1}$ This carcinoma is often preceded by a potentially malignant condition known as actinic cheilitis (AC), 
whose risk factors are the same as those of LLSCC and which could be involved in the initial stage of lip carcinogenesis. ${ }^{2}$ The biological and molecular processes involved in LLSCC tumorigenesis have not been fully elucidated yet.

The human leukocyte antigen-DR (HLA-DR) is a cell surface receptor of the major histocompatibility complex class II (MHC-II), encoded in MHC genomic region, on the short arm of chromosome 6 at $6 \mathrm{p} 21.31$. $^{3,4}$ Besides being found in antigen-presenting cells, $\mathrm{B}$ lymphocytes, activated Tlymphocytes, and endothelial cells, HLA-DR expression has been described in the parenchyma of several malignant tumors of different embryonic origins. $4,5,6,7$

Studies have shown a strong association between the high expression of HLA-DR in malignant neoplastic cells and a favorable prognosis in patients with esophageal adenocarcinoma ${ }^{4}$ and colorectal carcinoma. ${ }^{7}$ Accordingly, investigations have suggested that HLA-DR expression by tumor cells stimulates the activation of CD4+ T helper 1 (Th1) lymphocytes and natural killer (NK) cells through presentation of tumor antigens. This process would trigger the production of Th1 cytokines, such as interferon gamma (IFN- $\gamma$ ), leading to larger genetic instability of tumor cells, activation of M1 macrophages and consequent destruction of neoplastic cells. ${ }^{8,9}$ On the other hand, recent investigations have suggested that the expression of this molecule in neoplastic cells may be involved in protumoral activities. ${ }^{10,11}$

HLA-DR expression has also been evidenced in tumor cells of oral squamous cell carcinoma (SCC). ${ }^{5,6,12}$ However, investigations into a potential relationship between the expression of this protein in the parenchyma of oral SCC and the biological behavior of these malignancies are scarce and have presented conflicting findings. ${ }^{5,6}$ In the context of lip carcinogenesis, little is known to date about a possible role of HLA-DR in the pathogenesis and progression of AC and LLSCC. Therefore, the present study aimed to assess the immunoexpression of HLA-DR in cases of AC and LLSCC and to correlate it with clinicopathological features, thus shedding further light upon the mechanisms underlying lip carcinogenesis.

\section{Methodology}

Seventy-two specimens were selected for this study. Twenty-four cases of AC were obtained from the archives of the Laboratory of Oral Pathology, Department of Dentistry, State University of Paraíba (UEPB). Forty-eight cases of LLSCC were obtained from the archives of the Pathological Anatomy Service of Napoleão Laureano Hospital. Only cases of AC exhibiting solar elastosis were included in the sample. For LLSCCs, only cases derived from surgical resections were included in the study. Cases of AC previously treated with vitamin-containing creams or anti-inflammatory drugs were excluded. Patients with LLSCC subjected to radiation therapy, chemotherapy, or any other treatment before surgery were also excluded. Patient gender and age and anatomical location of the lesions were collected for all cases. Data regarding tumor size/extent, regional lymph node metastasis, distant metastasis, and clinical stage (TNM) were collected from medical records. The parameters of the sixth edition of the TNM Classification of Malignant Tumors were used for clinical staging. ${ }^{13}$ This study was approved by the Institutional Ethics Committee on Research Involving Humans (Protocol 69911217.0.0000.5187).

\section{Morphological analysis}

For the morphological analysis, $5-\mu \mathrm{m}$-thick sections were obtained from paraffin-embedded tissue blocks, deparaffinized, and stained with hematoxylin and eosin. Two previously trained examiners, who were unaware of the clinical data of the cases, analyzed the specimens under a light microscope (Leica DM 500; Leica Microsystems Vertrieb GmbH, Wetzlar, Germany).

The binary grading system, with modifications, was applied for grading epithelial dysplasia in AC. Cases with mild dysplasia were classified as lowgrade and cases with moderate or severe dysplasia as high-grade. ${ }^{14,15,16}$ In addition, the intensity of the inflammatory infiltrate was semiquantitatively evaluated along the connective tissue immediately beneath the epithelial lining. Using an adaptation of the method proposed by von Bubnoff et al., ${ }^{17}$ cases were classified according to the following scores: 
absent ( $\leq 25 \%$ of all cells were inflammatory cells), mild (26-50\% of all cells were inflammatory cells), moderate (51-75\% of all cells were inflammatory cells), and intense ( $\geq 76 \%$ of all cells were inflammatory cells).

For LLSCC, the histopathological grade of malignancy was evaluated at the deep invasive margins using the system proposed by Bryne et al., ${ }^{18}$ in which scores (1-4) are attributed to the following parameters: degree of keratinization, pattern of invasion, nuclear pleomorphism, and inflammatory infiltrate. The scores were then summed to obtain a final score of malignancy for each case. Tumors with a final score $\leq 8$ were classified as low-grade malignancy and tumors with a final score $\geq 9$ were classified as high-grade malignancy. ${ }^{19}$

\section{Immunohistochemistry}

Three- $\mu$ m-thick sections were obtained from paraffin-embedded tissue blocks and mounted on glass slides prepared with organosilane adhesive. The tissue sections were deparaffinized, rehydrated, and subjected to antigen retrieval with citrate buffer, $\mathrm{pH} 6.0$, at $90^{\circ} \mathrm{C}$ in a steamer for $60 \mathrm{~min}$. The sections were then immersed in $3 \%$ hydrogen peroxide to block endogenous peroxidase activity and incubated with the primary anti-HLA-DR antibody (dilution 1:800, clone TAL.1B5; Dako, Carpinteria, USA) in a humidity chamber for $60 \mathrm{~min}$. After incubation with the primary antibody, the sections were washed in Tris- $\mathrm{HCl}$ buffer and treated with a polymer-based complex (Reveal $^{\mathrm{TM}}$; Spring Bioscience Corp., Pleasanton, USA). Diaminobenzidine was used to visualize peroxidase activity (DAB Substrate system; Spring Bioscience Corp., Pleasanton, USA), which resulted in a brown reaction product. Finally, the sections were counterstained with Mayer's hematoxylin, dehydrated, and coverslipped. Samples of periapical granulomas were used as positive control. The negative control consisted of omission of the primary antibody in the protocol described above.

\section{Immunohistochemical analysis}

The immunohistochemical analysis was performed blindly under a light microscope (Leica DM 500; Leica Microsystems Vertrieb GmbH, Wetzlar, Germany) by two previously trained observers. HLA-DR expression was analyzed only in epithelial cells of AC and LLSCC. In AC, HLA-DR immunoexpression was evaluated along the epithelial lining. In LLSCC, the expression of this protein was analyzed at the deep invasive front.

HLA-DR immunoexpression was evaluated quantitatively using an adaptation of the method proposed by Lúcio et al..$^{20}$ At $100 \times$ magnification, the fields ( 5 for AC and 10 for LLSCC) containing the largest number of immunostained cells were identified. At 400× magnification, digital images of these microscopic fields were acquired with a Leica ICC 50HD camera (Leica Microsystems Vertrieb $\mathrm{GmbH}$, Wetzlar, Germany) and transferred to the ImageJ ${ }^{\circledR}$ program (National Institute of Mental Health, Bethesda, USA). The number of positive and negative cells was determined in each field and the percentage of cells exhibiting cytoplasmic and/or membrane staining for HLA-DR was calculated for each case. After establishing the percentage of immunopositive cells, cases were classified according to the following scores: $0=<1 \%, 1=1-5 \%, 2=6-25 \%$, $3=26-50 \%, 4=51-75 \%$, and $5=>75 \%{ }^{21}$

\section{Statistical analysis}

The clinical, morphological, and immunohistochemical results were subjected to statistical analysis using the IBM SPSS Statistics program (version 20.0; IBM Corp., Armonk, USA). Descriptive statistics was used for characterization of the sample. The results of HLA-DR immunoexpression in AC were only subjected to descriptive statistical analysis because of the small number of positive cases. In LLSCC, the nonparametric Mann-Whitney test was used to compare the median score of positive cells for HLA-DR according to the different clinicopathological parameters. The significance level was set at $5 \%$ for all tests $(\mathrm{p}<0.05)$.

\section{Results}

\section{Clinical and morphological data}

The clinical and histopathological results are summarized in Table. Most cases of AC were diagnosed in men (91.7\%), corresponding to a male-to-female ratio of 11:1. Patient age ranged from 25 to 70 years, with a mean 
of $51.3 \pm 13.1$ years. Regarding epithelial dysplasia in ACs, there was a similar frequency of low-grade (50.0\%) and high-grade $(50.0 \%)$ lesions in the sample. Analysis of the intensity of the inflammatory infiltrate in ACs revealed a higher frequency of cases with moderate (41.7\%) and mild (29.2\%) inflammatory infiltrate.

Table. Distribution of cases of AC and LLSCC according to clinicopathological parameters.

\begin{tabular}{|c|c|}
\hline Variable & n (\%) \\
\hline \multicolumn{2}{|l|}{$A C$} \\
\hline \multicolumn{2}{|l|}{ Gender } \\
\hline Male & $22(91.7)$ \\
\hline Female & $2(8.3)$ \\
\hline \multicolumn{2}{|c|}{ Grade of epithelial dysplasia } \\
\hline Low-grade & $12(50.0)$ \\
\hline High-grade & $12(50.0)$ \\
\hline \multicolumn{2}{|c|}{ Inflammatory infiltrate } \\
\hline Absent & $2(8.3)$ \\
\hline Mild & $7(29.2)$ \\
\hline Moderate & $10(41.7)$ \\
\hline Intense & $5(20.8)$ \\
\hline \multicolumn{2}{|l|}{ LLSCC } \\
\hline \multicolumn{2}{|l|}{ Gender } \\
\hline Male & $35(72.9)$ \\
\hline Female & $13(27.1)$ \\
\hline \multicolumn{2}{|l|}{ Tumor } \\
\hline T1 & $16(33.3)$ \\
\hline $\mathrm{T} 2$ & $24(50.0)$ \\
\hline Т3 & $5(10.4)$ \\
\hline T4 & $3(6.3)$ \\
\hline \multicolumn{2}{|l|}{ Node } \\
\hline NO & $24(50.0)$ \\
\hline N1 & $17(35.4)$ \\
\hline N2 & $6(12.5)$ \\
\hline N3 & $1(2.1)$ \\
\hline \multicolumn{2}{|l|}{ Metastasis } \\
\hline MO & $45(93.8)$ \\
\hline M1 & $3(6.2)$ \\
\hline \multicolumn{2}{|l|}{ Clinical stage } \\
\hline Stage I & $9(18.8)$ \\
\hline Stage II & $14(29.2)$ \\
\hline Stage III & $14(29.2)$ \\
\hline Stage IV & $11(22.9)$ \\
\hline \multicolumn{2}{|c|}{ Histopathological grade } \\
\hline Low-grade & $15(31.2)$ \\
\hline High-grade & $33(68.8)$ \\
\hline
\end{tabular}

Regarding LLSCC, 35 (72.9\%) out of 48 cases were diagnosed in men, corresponding to a male-to-female ratio of 2.7:1. Patient age ranged from 26 to 97 years, with a mean of $63.6 \pm 18.9$ years. With respect to tumor size/extent and regional lymph node metastasis, there was a higher frequency of cases classified as T2 (50.0\%) and N0 (50.0\%). Distant metastases were observed in only three cases (6.2\%). The most frequent clinical stages were stage II (29.2\%) and stage III (29.2\%). Regarding histopathological grade, there was a predominance of high-grade tumors in the sample (68.8\%).

\section{Immunohistochemical analysis}

Analysis of the epithelial immunoexpression of HLA-DR revealed positivity in only five $(20.8 \%)$ cases of AC (two low-grade and three high-grade lesions), with a median score of positive cells of 0.0 (range: 0.0-1.0). In the few HLA-DR-positive cases (one with mild inflammatory infiltrate, three with moderate inflammatory infiltrate, and one with intense inflammatory infiltrate), expression of this protein was found predominantly in the lower third of the epithelium (Figure 1, A-B). The epithelial lining of normal-appearing vermilion border and oral mucosa, found in some cases of AC, was negative for HLA-DR.

In LLSCC, HLA-DR immunoexpression was observed in $47(97.9 \%)$ out of 48 cases (Figure 1, C-D), with a median score of positive cells of 4.0 (range: 0.0-5.0). With respect to tumor size/extent, the median score of HLA-DR-positive cells was 4.0 (range: $2.0-5.0$ ) in SCC classified as T1 and 4.5 (range: $0.0-5.0)$ in tumors classified as T2-T4. This difference was not statistically significant ( $p=0.837$ ) (Figure 2).

Regarding regional lymph node metastasis, the median score of cytoplasmic/membrane staining for HLA-DR was 3.5 (range: 0.0-5.0) in tumors without metastases and 5.0 (range: 2.0-5.0) in tumors with metastases, but the difference was not statistically significant $(p=0.222)$ (Figure 2$)$. With respect to the clinical stage of LLSCC, the median score of HLA-DR-positive cells was 4.0 (range: $0.0-5.0$ ) in early clinical stages (I/ II) and 5.0 (range: 2.0-5.0) in advanced clinical stages (III/ IV). The nonparametric Mann-Whitney test revealed no statistically significant differences between the groups $(p=0.320)$ (Figure 2). 

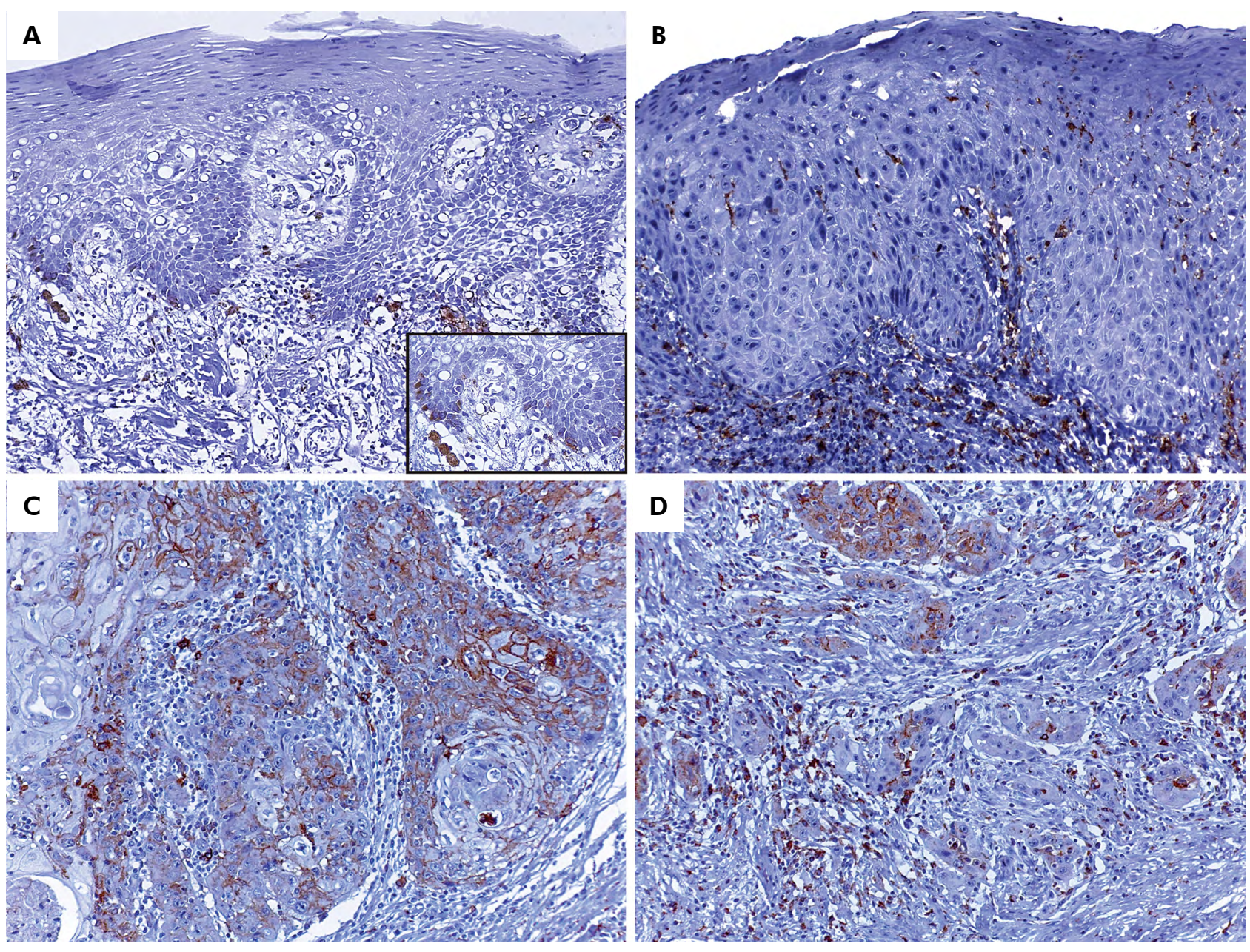

Figure 1. A) Few HLA-DR-positive epithelial cells in the epithelium of AC (Reveal $\left.{ }^{T M}, 200 \times\right)$. B) No expression of HLA-DR in epithelial cells of $A C$ and strong immunoreactivity to this protein in intraepithelial dendritic cells and inflammatory cells in the connective tissue $($ RevealTM, 200x). C) Immunoexpression of HLA-DR at the invasive front of low-grade LLSCC with regional lymph node metastasis $\left(\right.$ Reveal $\left.^{T M}, 200 \times\right)$. D) Immunoexpression of HLA-DR at the invasive front of high-grade LLSCC (Reveal $\left.{ }^{\text {TM }}, 200 \times\right)$.

Analysis of the score of cytoplasmic/membrane staining for HLA-DR according to histopathological grade of malignancy revealed a median number of 5.0 (range: 2.0-5.0) in low-grade tumors and of 4.0 (range: $0.0-5.0)$ in high-grade tumors. This difference was not statistically significant $(p=0.164$ ) (Figure 2 ). The score of HLA-DR-positive cells tended to be higher in highly/ moderately keratinized tumors and in tumors with little/moderate nuclear pleomorphism $(p>0.05)$ (Figure 3). No statistically significant difference in HLA-DR immunoexpression was observed regarding the intensity of inflammatory infiltrate in LLSCC $(p=0.947)$ (Figure 3). Furthermore, tumors with clearly defined infiltrative borders or those arranged in cords, bands, or solid trabeculae exhibited a similar percentage of
HLA-DR-positive cells when compared with tumors arranged in small cell clusters $(p=0.817)$ (Figure 3 ).

\section{Discussion}

A controversial role of MHC-II molecules, including HLA-DR, has been evidenced in malignant tumors. The expression of these molecules in tumor cells may play different roles in the biological behavior of tumors, sometimes triggering an antitumor immune response, leading to apoptosis of neoplastic cells, or eliciting protumoral functions, favoring tumor growth. .11,22-24 $^{2}$ The present study demonstrated for the first time a higher HLA-DR expression in LLSCC tumor cells when compared to cases of $\mathrm{AC}$, suggesting a potential 

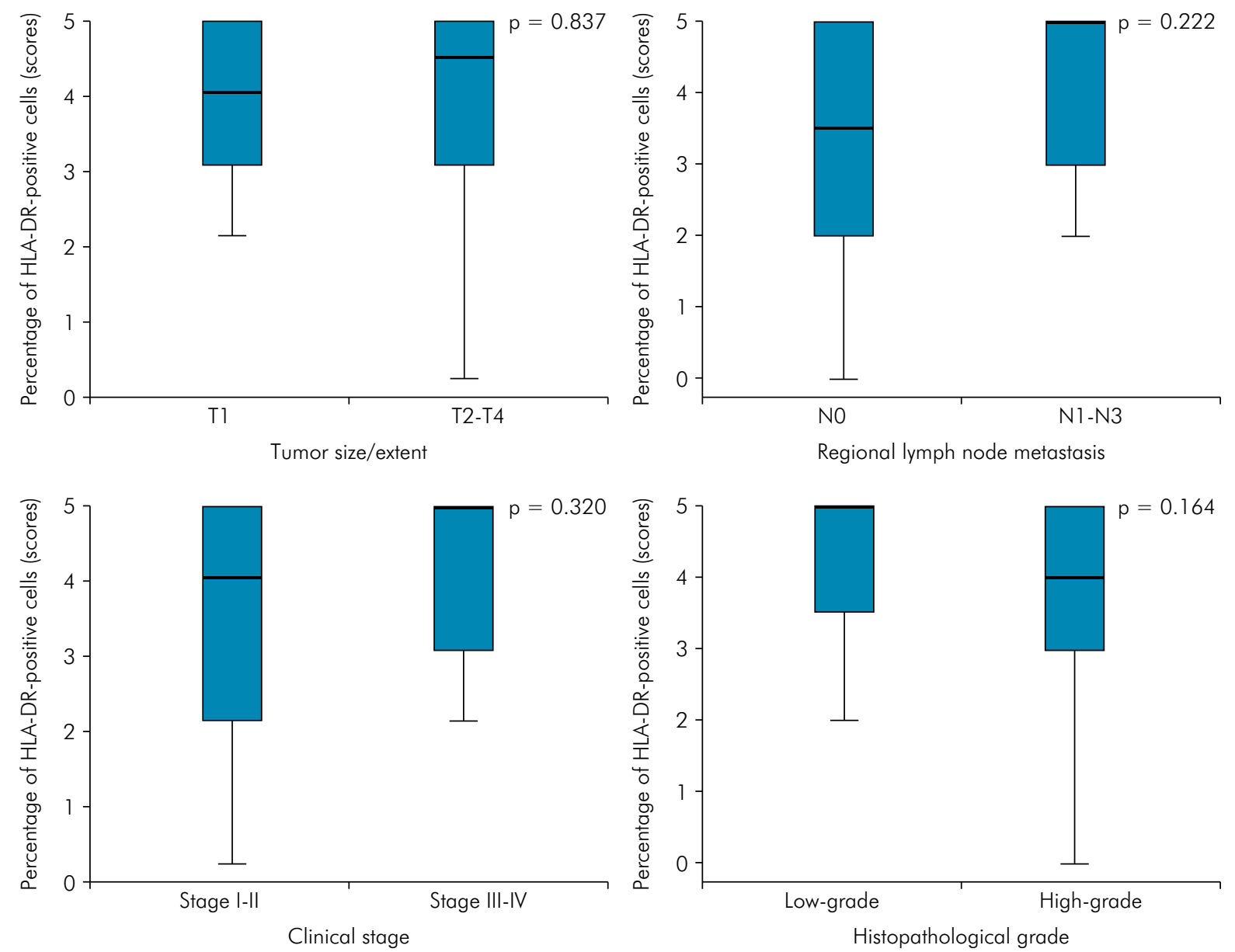

Figure 2. Box plot charts illustrating the scores of HLA-DR-positive cells in LLSCC according to tumor size/extent, regional lymph node metastasis, clinical stage, and histopathological grade of malignancy.

role of this protein in tumor and immunostimulatory events in LLSCC.

Unlike MHC-I molecules, which are expressed in all nucleated cells, the expression of MHC-II proteins is physiologically observed only in some cell types, including dendritic cells, phagocytes, endothelial cells, and thymic epithelial cells, which have a large capacity for antigen presentation. ${ }^{25,26}$ The role of HLA-DR expression in normal lip epithelium and in potentially malignant lesions derived from this tissue is not fully known. Dunne et al. $^{4}$ found epithelial expression of HLA-DR in cases of esophagitis, Barrett's esophagus, and Barrett's esophagus with dysplasia, suggesting activity of this protein from the very first stages of esophageal adenocarcinoma.

In our study, few cases of $\mathrm{AC}$ were immunoreactive to HLA-DR (20.8\%), with a very low median score of positivity. Note also that the epithelial expression of HLA-DR in AC was observed both in low-grade and high-grade lesions, most of them exhibiting moderate inflammatory infiltrate. Together, these findings suggest a minor role of HLA-DR in initial stages of lip carcinogenesis. In this case, cytokines released by inflammatory cells present in the microenvironment of AC could stimulate the antigen-presenting machinery in epithelial cells and trigger immune responses that would contribute to the pathogenesis of these lesions. Conversely, HLA-DR expression would not be related to the progression of morphological changes in AC.

In the investigated LLSCC, HLA-DR expression was observed in most of the cases (97.9\%). Likewise, the expression of this protein has also been described in other malignant tumors, including esophageal adenocarcinoma, ${ }_{1}^{4}$ gastric adenocarcinoma, ${ }_{11}^{11}$ colorectal 

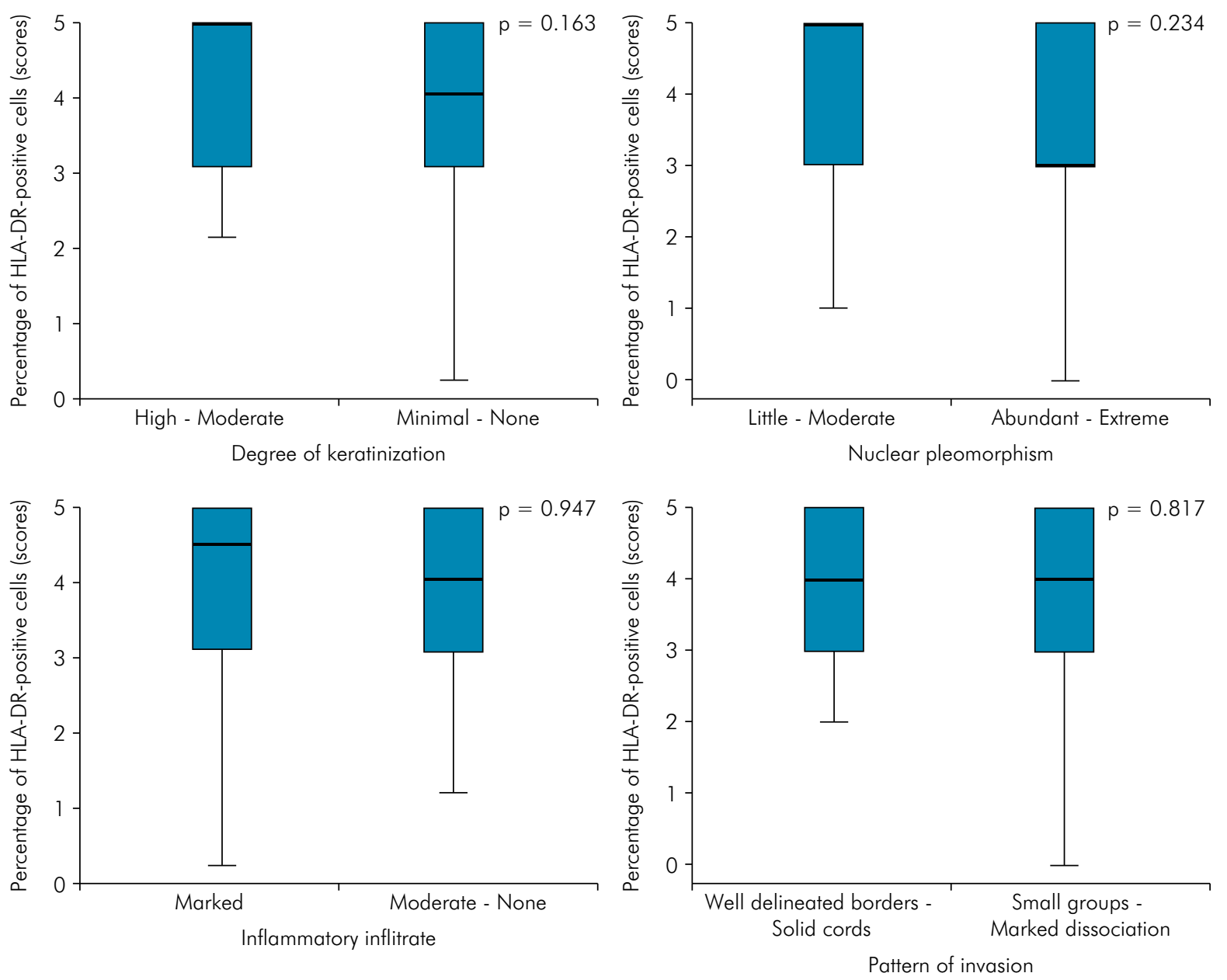

Figure 3. Box plot charts illustrating the scores of HLA-DR-positive cells in LLSCC according to degree of keratinization, nuclear pleomorphism, pattern of invasion, and inflammatory infiltrate.

carcinoma, ${ }^{7}$ and oral SCC. ${ }^{5,6,12}$ HLA-DR expression in neoplasms is commonly related to the presence of inflammatory cells, such as CD16 ${ }^{+}$myeloid cells, and to the development of subpopulations of CD4 T lymphocytes. ${ }^{727}$ However, it is still unclear whether the high expression of HLA-DR in neoplastic cells precedes or results from inflammatory infiltrate in the tumors. ${ }^{4}$ It has been suggested that early infiltration of inflammatory mononuclear cells in the tumor microenvironment stimulates the synthesis of IFN- $\gamma$ and of other inflammatory cytokines, which increase HLA-DR expression and further heighten the immune response by subsequent activation of effector T cells. ${ }^{28,29}$ As LLSCCs often have large amounts of $\mathrm{T}$ lymphocyte subpopulations at the invasive front, ${ }^{30}$ these inflammatory cells might be stimulated, leading to HLA-DR expression in tumor cells and triggering a positive feedback from the interaction between them.

The clinical significance of HLA-DR expression in malignant tumors remains unclear. While some studies associate the high expression of HLA-DR in solid tumors with favorable outcomes, ${ }^{4,7}$ others suggest that the overexpression of this molecule could indicate a worse prognosis. ${ }^{10,11}$ In the case of oral SCC, Li, Zhang and Tong, ${ }^{6}$ using immunohistochemistry and in situ hybridization, observed a higher HLA-DR expression in primary carcinomas when compared to the healthy oral mucosa $(\mathrm{p}<0.05)$, but they did not find any statistically significant differences in the immunoexpression of this protein between metastatic lesions and primary carcinomas. Horiuchi et al. ${ }^{5}$ found a statistically significant association between immunoreactivity to HLA-DR in well-differentiated 
intraoral SCC tumor cells and lower five-year survival rate of patients. In the present study, despite the lack of statistical significance, LLSCC with regional lymph node metastases and in clinically advanced stages showed a higher HLA-DR expression, suggesting a possible role of this protein in the modulation of events related to tumor progression.

Among the possible factors related to the negative impact of the expression of MHC-II molecules, including HLA-DR, in parenchymal and inflammatory cells of malignant solid tumors, loss or absence of costimulatory molecules in these cells has been suggested, leading to T cell anergy because of the presence of immunosuppressive cytokines produced by tumor cells. ${ }^{22}$ It is also possible that MHC-II proteins could facilitate the engulfment of $\mathrm{T}$ cells by tumor cells. ${ }^{23,24}$

In our study, we noted a tendency towards higher HLA-DR expression in low-grade tumors, which probably results from the high expression of this protein in highly/moderately keratinized tumors or in those with low/moderate nuclear pleomorphism. These findings suggest that genetic and epigenetic changes in tumorigenesis, as well as interaction of tumor cells with components of the tumor microenvironment, could increase antigen presentation in cells with higher degree of cell differentiation. However, this arsenal appears to be gradually lost with the lack of cell differentiation, indicating a possible interplay of HLA-DR expression with the differentiation of tumor cells in LLSCC. Given that in other malignant neoplasms, such as colorectal carcinomas, ${ }^{7}$ the expression of this molecule is not related to the histological grade of the tumor, further investigation is needed to elucidate the mechanisms that regulate HLA-DR expression regarding cell differentiation in LLSCC.

Even though a larger number of inflammatory cells was expected in LLSCC with higher epithelial expression of HLA-DR, the findings of this study reveal lack of significant difference in immunoreactivity to this protein regarding the intensity of the inflammatory infiltrate at the invasive front of these neoplasms. It should be highlighted, however, that not only the amount of inflammatory infiltrate, but mainly qualitative changes in the subpopulations of inflammatory cells may significantly influence events that predispose to tumor immunosuppression in LLSCC. ${ }^{31}$ Among these events, special attention should be given to the high levels of IL-10, the expression of HLA-G and HLA-E by inflammatory cells, ${ }^{32}$ and the presence of M2 tumor-associated macrophages. ${ }^{20}$

\section{Conclusion}

The findings of this study show a higher HLA-DR immunoexpression in LLSCC than in AC, the latter of which was mostly negative for this protein. Together, these findings suggest a possible role of HLA-DR in lip carcinogenesis, particularly in the progression of LLSCC. In these tumors, HLA-DR expression may be related to the degree of cell differentiation.

\section{Acknowledgements}

This work was supported by Programa Institucional de Iniciação Científica - UEPB/ National Council for Scientific and Technological Development (CNPq). CFWN is a research fellow at CNPq.

\section{References}

1. Scully C, Bagan J. Oral squamous cell carcinoma: overview of current understanding of aetiopathogenesis and clinical implications. Oral Dis. 2009 Sep;15(6):388-99. https://doi.org/10.1111/j.1601-0825.2009.01563.x

2. Ribeiro AO, Silva LC, Martins-Filho PR. Prevalence of and risk factors for actinic cheilitis in Brazilian fishermen and women. Int J Dermatol. 2014 Nov;53(11):1370-6. https://doi.org/10.1111/ijd.12526

3. Shiina T, Hosomichi K, Inoko H, Kulski JK. The HLA genomic loci map: expression, interaction, diversity and disease. J Hum Genet. 2009 Jan;54(1):15-39. https://doi.org/10.1038/ihg.2008.5

4. Dunne MR, Michielsen AJ, O'Sullivan KE, Cathcart MC, Feighery R, Doyle B, et al. HLA-DR expression in tumor epithelium is an independent prognostic indicator in esophageal adenocarcinoma patients. Cancer Immunol Immunother. 2017 Jul;66(7):841-50. https://doi.org/10.1007/s00262-017-1983-1 
5. Horiuchi K, Mishima K, Ohsawa M, Sugimura M, Aozasa K. Prognostic factors for well-differentiated squamous cell carcinoma in the oral cavity with emphasis on immunohistochemical evaluation. J Surg Oncol. 1993 Jun;53(2):92-6. https://doi.org/10.1002/jso.2930530209

6. Li L, Zhang S, Tong M. [Human leukocyte antigen-DR expression and transcription in oral squamous cell carcinomas]. Hua Xi Kou Qiang Yi Xue Za Zhi. 2003 Feb;21(1):48-51.

7. Sconocchia G, Eppenberger-Castori S, Zlobec I, Karamitopoulou E, Arriga R, Coppola A, et al. HLA class II antigen expression in colorectal carcinoma tumors as a favorable prognostic marker. Neoplasia. 2014 Jan;16(1):31-42. https://doi.org/10.1593/neo.131568

8. Armstrong TD, Clements VK, Ostrand-Rosenberg S. MHC class II-transfected tumor cells directly present antigen to tumor-specific CD4+ T lymphocytes. J Immunol. 1998 Jan;160(2):661-6.

9. Garnier A, Hamieh M, Drouet A, Leprince J, Vivien D, Frébourg T, et al. Artificial antigen-presenting cells expressing HLA class II molecules as an effective tool for amplifying human specific memory CD4(+) T cells. Immunol Cell Biol. 2016 Aug;94(7):662-72. https://doi.org/10.1038/icb.2016.25

10. Diao J, Xia T, Zhao H, Liu J, Li B, Zhang Z. Overexpression of HLA-DR is associated with prognosis of glioma patients. Int J Clin Exp Pathol. 2015 May;8(5):5485-90.

11. Yavorski JM, Blanck G. MHC class II associated stomach cancer mutations correlate with lack of subsequent tumor development. Mol Clin Oncol. 2017 Dec;7(6):1119-21. https://doi.org/10.3892/mco.2017.1432

12. Heyden A, Thrane PS, Brandtzaeg P. Loss of epithelial L1 expression is associated with cellular invasion of oral squamous cell carcinomas. J Oral Pathol Med. 1992 Aug;21(7):330-5. https://doi.org/10.1111/j.1600-0714.1992.tb01021.x

13. Sobin LH, Wittekind C. TNM classification of malignant tumors. 6th ed. New Jersey: John Wiley \& Sons; 2002.

14. Warnakulasuriya S, Reibel J, Bouquot J, Dabelsteen E. Oral epithelial dysplasia classification systems: predictive value, utility, weaknesses and scope for improvement. J Oral Pathol Med. 2008 Mar;37(3):127-33. https://doi.org/10.1111/j.1600-0714.2007.00584.x

15. Reibel J, Gale N, Hille J, Hunt JL, Lingen M, Muller S, et al. Oral potentially malignant disorders and oral epithelial dysplasia. In: El-Naggar AK, Chan JK, Grandis JR, Takata T, Slootweg PJ, editors. WHO classification of head and neck tumours. 4th ed. Lyon: IARC Press; 2017. p. 112-4.

16. Kujan O, Oliver RJ, Khattab A, Roberts SA, Thakker N, Sloan P. Evaluation of a new binary system of grading oral epithelial dysplasia for prediction of malignant transformation. Oral Oncol. 2006 Nov;42(10):987-93. https://doi.org/10.1016/i.oraloncology.2005.12.014

17. Bubnoff D, Zahn S, Wenzel J, Wilms H, Bieber T, Lüftl M. Indoleamine 2,3-dioxygenase expression in early keratocyte neoplasia of the lower lip correlates to the degree of cell atypia. Pathol Int. 2012 Feb;62(2):105-11. https://doi.org/10.1111/j.1440-1827.2011.02757.x

18. Bryne M, Koppang HS, Lilleng R, Kjaerheim A. Malignancy grading of the deep invasive margins of oral squamous cell carcinomas has high prognostic value. J Pathol. 1992 Apr;166(4):375-81. https://doi.org/10.1002/path.1711660409

19. Silveira EJ, Godoy GP, Lins RD, Arruda ML, Ramos CC, Freitas RA, et al. Correlation of clinical, histological, and cytokeratin profiles of squamous cell carcinoma of the oral tongue with prognosis. Int J Surg Pathol. 2007 Oct;15(4):376-83. https://doi.org/10.1177/1066896907304992

20. Lúcio PS, Ribeiro DC, Aguiar MC, Alves PM, Nonaka CF, Godoy GP. Tumor-associated macrophages (TAMs): clinical-pathological parameters in squamous cell carcinomas of the lower lip. Braz Oral Res. 2016 Aug;30(1):e95. https://doi.org/10.1590/1807-3107BOR-2016.vol30.0095

21. Cioni B, Jordanova ES, Hooijberg E, Linden R, Menezes RX, Tan K, et al. HLA class Il expression on tumor cells and low numbers of tumor-associated macrophages predict clinical outcome in oropharyngeal cancer. Head Neck. 2019 Feb;41(2):463-78. https://doi.org/10.1002/hed.25442

22. Macián F, Im SH, García-Cózar FJ, Rao A. T-cell anergy. Curr Opin Immunol. 2004 Apr;16(2):209-16. https://doi.org/10.1016/i.coi.2004.01.013

23. Lugini L, Matarrese P, Tinari A, Lozupone F, Federici C, lessi E, et al. Cannibalism of live lymphocytes by human metastatic but not primary melanoma cells. Cancer Res. 2006 Apr;66(7):3629-38. https://doi.org/10.1158/0008-5472.CAN-05-3204

24. Lloyd MC, Szekeres K, Brown JS, Blanck G. Class II transactivator expression in melanoma cells facilitates T-cell engulfment. Anticancer Res. 2015 Jan;35(1):25-9.

25. Samuels S, Spaans VM, Osse M, Peters LA, Kenter GG, Fleuren GJ, et al. Human leukocyte antigen-DR expression is significantly related to an increased disease-free and disease-specific survival in patients with cervical adenocarcinoma. Int J Gynecol Cancer. 2016 Oct;26(8):15039. https://doi.org/10.1097/IGC.0000000000000783

26. Abbas A, Lichtman AH, Pillai S. Cellular and Molecular Immunology. 9th ed. Philadelphia: Elsevier/ Saunders; 2018.

27. Thibodeau J, Bourgeois-Daigneault MC, Lapointe R. Targeting the MHC Class II antigen presentation pathway in cancer immunotherapy. Oncolmmunology. 2012 Sep;1(6):908-16. https://doi.org/10.4161/onci.21205

28. Albanesi C, Cavani A, Girolomoni G. Interferon-gamma-stimulated human keratinocytes express the genes necessary for the production of peptide-loaded MHC class II molecules. J Invest Dermatol. 1998 Feb;110(2):138-42. https://doi.org/10.1046/j.1523-1747.1998.00098.x

29. Mulder DJ, Pooni A, Mak N, Hurlbut DJ, Basta S, Justinich CJ. Antigen presentation and MHC class II expression by human esophageal epithelial cells: role in eosinophilic esophagitis. Am J Pathol. 2011 Feb;178(2):744-53. https://doi.org/10.1016/i.ajpath.2010.10.027

30. Silveira EJ, Miguel MC, Lima KC, Freitas RA, Morais ML, Queiroz LM. Analysis of local immunity in squamous cell carcinoma of the tongue and lower lip. Exp Mol Pathol. 2010 Feb;88(1):171-5. https://doi.org/10.1016/i.yexmp.2009.11.009

31. Gomes JO, Carvalho MV, Fonseca FP, Gondak RO, Lopes MA, Vargas PA. CDla+ and CD83+ Langerhans cells are reduced in lower lip squamous cell carcinoma. J Oral Pathol Med. 2016 Jul;45(6):433-9. https://doi.org/10.1111/jop.12389

32. Gonçalves AS, Oliveira JP, Oliveira CF, Silva TA, Mendonça EF, Wastowski IJ, et al. Relevance of HLA-G, HLA-E and IL-10 expression in lip carcinogenesis. Hum Immunol. 2016 Sep;77(9):785-90. https://doi.org/10.1016/i.humimm.2015.12.001 